\title{
Histopathology of nephrectomy specimens: A ten year south Indian tertiary hospital based study
}

\author{
Chaitra. $\mathrm{B}^{1, *}$, Prema Latha $\mathrm{P}^{2}$, Tejeswini $\mathrm{V}^{3}$, Haritha $\mathrm{O}^{4}$, Anusha $\mathrm{M}^{5}$ \\ ${ }^{\mathbf{1}}$ Assistant Professor, ${ }^{2}$ Profesor and HOD, ${ }^{3}$ Professor ${ }^{4,5}$ Postgraduate, Dept. of Pathology, NRI Medical College, Chinakakani, \\ Guntur, Andhra Pradesh, India
}

*Corresponding Author:

Email: chaitra.b@gmail.com

\begin{abstract}
Introduction: Nephrectomies are an integral part of urological practice and a wide range of renal diseases are seen on histopathological examination of nephrectomy specimens.

Aim: This study was conducted to evaluate the neoplastic and non neoplastic conditions encountered in nephrectomy specimens that were received in our department over a ten year period and compare it with other studies.

Materials and Methods: A hospital-based ten year retrospective study of all nephrectomy specimens received in the department of Pathology.

Results: A total of 177 nephrectomy specimens were studied. $54.3 \%$ cases were male patients with peak during $5^{\text {th }}-6^{\text {th }}$ decade. $63.8 \%$ cases were non neoplastic lesions and $36.2 \%$ neoplastic lesions.

Conclusion: Inflammatory causes more commonly required a nephrectomy in this study. The commonest indication for nephrectomy was chronic pyelonephritis followed by clear cell renal cell carcinoma.
\end{abstract}

Keywords: Nephrectomies, Chronic pyelonephritis, Clear cell RCC, Histopathology.

\section{Introduction}

Kidney plays a vital role in excretion of waste product, water and electrolyte metabolism along with acid base balance, maintenance of blood pressure by secretion of renin-angiotensin and regulation of erythropoiesis by erythropoietin. ${ }^{1}$ Kidney can be involved in various pathological processes, both neoplastic and non neoplastic conditions, some of which may require its surgical removal, nephrectomy. ${ }^{2}$ A wide variety of both benign and malignant tumours arise from different components of the renal parenchyma, notably tubular epithelium. ${ }^{3}$

Chronic pyelonephritis, and hydronephrosis are the most common types of nephrectomy specimen for nonneoplastic conditions, whereas in the neoplastic group, renal cell carcinoma is the most common in adults and Wilms tumour in childhood. ${ }^{4}$

Aim: This study was conducted to evaluate the neoplastic and non neoplastic conditions encountered in nephrectomy specimens that were received in our department over a ten year period. To analyze the frequency of non neoplastic and neoplastic renal lesions, assess age and sex wise distribution of various renal lesions and compare it with other studies.

\section{Materials and Methods}

This is a retrospective study conducted in Department of Pathology on 177 consecutive nephrectomies performed at NRI Medical College and General Hospital, Chinakakani, during the ten year period of January 2008 to December 2017.
Only nephrectomy specimens both simple and radical were included in this study. Core needle biopsies from renal masses were excluded. Tumours of ureter and pelvis were excluded from statistical analysis. Age, sex and gross findings were retrieved from the records. These parameters were compared with the available data in the literature. All the specimens were fixed in $10 \%$ formol - saline, then processed into paraffin embedded sections \& stained with haematoxylin \& eosin. A final histopathological diagnosis was made by a panel of pathologists after reviewing the slides. Frequency of various conditions leading to nephrectomy was listed. Malignant tumours - Renal cell carcinomas (RCC) were graded using Furhams nuclear grading. ${ }^{5}$

\section{Results}

A total of 177 nephrectomy specimens were received out of which $64(36.2 \%)$ were neoplastic and $113(63.8 \%)$ were non neoplastic lesions. Among the 177 cases $96(54.3 \%)$ were male patients and 81 (45.7\%) female patients with a male to female ratio of 1.18:1. The age range varied widely according to the type of the disease. The youngest patient being a five month old female infant while oldest being 80 year old male. Patients operated for non neoplastic conditions were younger with a mean age of 38.9 years when compared to patients with neoplastic conditions where the mean age was 52.8 years.

The relative frequency of all the conditions leading to nephrectomy in this study is depicted in Table 1. 
Table 1

\begin{tabular}{|l|c|c|}
\hline \multicolumn{1}{|c|}{ Diagnosis } & Number of cases (N=177) & Percentage (\%) \\
\hline Chronic Pyelonephritis & 62 & 35.02 \\
\hline Clear cell RCC & 32 & 18.10 \\
\hline Hydronephrosis & 21 & 11.90 \\
\hline Xanthogranulomatous nephritis & 12 & 6.80 \\
\hline Papillary RCC & 10 & 5.66 \\
\hline Wilms tumor & 6 & 3.41 \\
\hline Tuberculosis & 5 & 2.82 \\
\hline Interstitial nephritis & 5 & 2.82 \\
\hline End stage renal disease & 3 & 1.69 \\
\hline Clear cell Papillary RCC & 3 & 1.69 \\
\hline Oncocytoma & 3 & 1.69 \\
\hline Angiomyolipoma & 3 & 1.69 \\
\hline Clear cell sarcoma of Kidney & 2 & 1.12 \\
\hline Simple renal cysts & 2 & 1.12 \\
\hline RCC Unclassified & 2 & 1.12 \\
\hline Multilocular Cystic renal neoplasm & 2 & 1.12 \\
\hline Hypoplastic cystic renal dysplasia & 1 & 0.56 \\
\hline Adult polycystic kidney & 1 & 0.56 \\
\hline Actinomycosis & 1 & 0.56 \\
\hline Tubulocystic RCC & 1 & 0.56 \\
\hline
\end{tabular}

Neoplastic Diseases: Renal neoplasms constituted 64 cases, clear cell RCC was the most common (32 cases) followed by Papillary RCC (10 cases). Other tumours included 6 cases of Wilms tumor, 3 cases of clear cell papillary RCC, oncocytoma and angiomyolipoma each, 2 cases of clear cell sarcoma of kidney, RCC unclassified and multinodular cystic renal neoplasm of low malignant potential and 1 case of tubulocystic RCC.

Among the 64 renal neoplastic conditions 41 cases were males and 23 were females with a male to female ratio of 1.78:1.

Among the 64 neoplastic lesions 58 cases were adults with a mean age of 57.7 years for adult renal neoplasms with majority of cases in fifth and sixth decade. 6 cases of childhood renal neoplasms were documented in this study with a mean age of 5.5 years.

A majority of 38 cases $(59.4 \%)$ showed tumor in left kidney, 25 cases (39\%) involving right kidney and one case $(1.6 \%)$ showed bilateral involvement.
The clear cell RCC was graded from 1 to 4 according to Fuhrman's nuclear grade. Nuclear Grade 2 tumours were most common followed by Grade 3 tumours.

Non Neoplastic Diseases: The non neoplastic lesions constituted 113 cases with chronic pyelonephritis being the commonest cause (62 cases), for nephrectomy. Other conditions leading to nephrectomy were hydronephrosis (21 cases), Xanthogranulomatous nephritis (12 cases), tuberculosis (5 cases), chronic interstitial nephritis (5 cases), end stage tubule interstitial disease (3 cases), simple renal cysts (2 cases), Hypoplastic cystic renal dysplasia (1 case), Adult polycystic kidney (1 case) and actinomycosis (1 case).

Among the 113 non neoplastic cases there was a slight female preponderance (58 cases) than the male patients (55 cases) with a male to female ratio of 0.94:1.

Majority of non neoplastic diseases were noted in 41-60 year age range (42 cases) followed by $21-40$ year age range (40 cases).

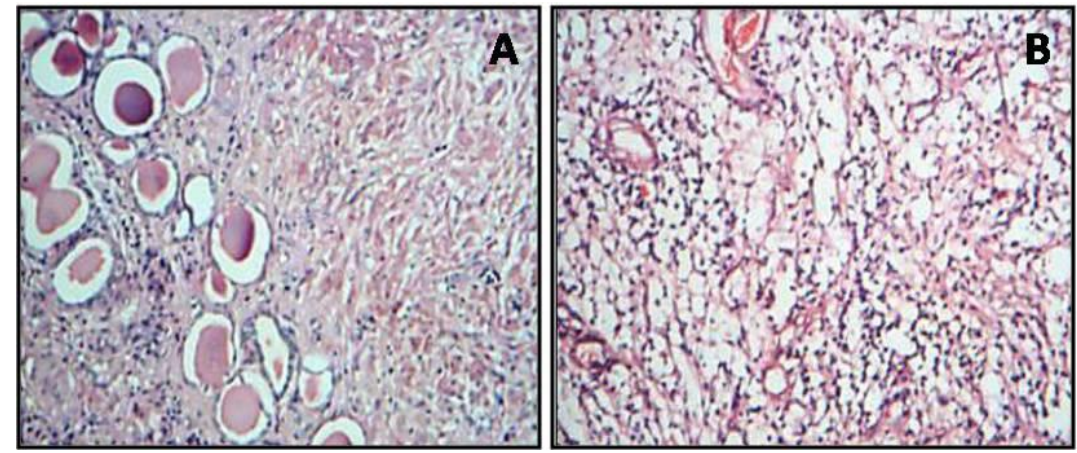

Fig. 1: A. Chronic pyelonephritis; (B): Xnthogranulomatous pyelonephritis 

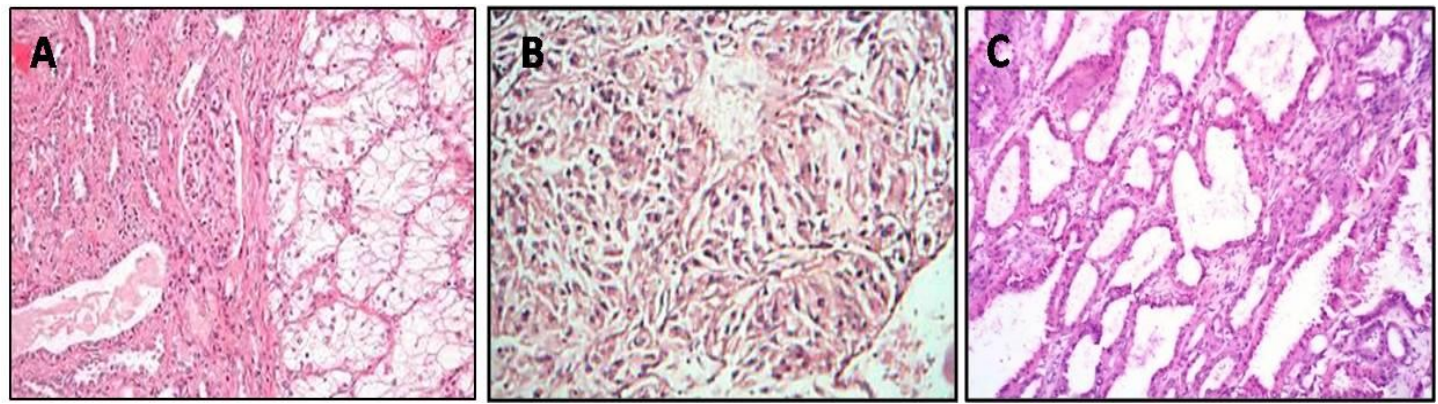

Fig. 2: (A): Clear cell RCC, (B): Papillary RCC, C. Tubulocystic RCC
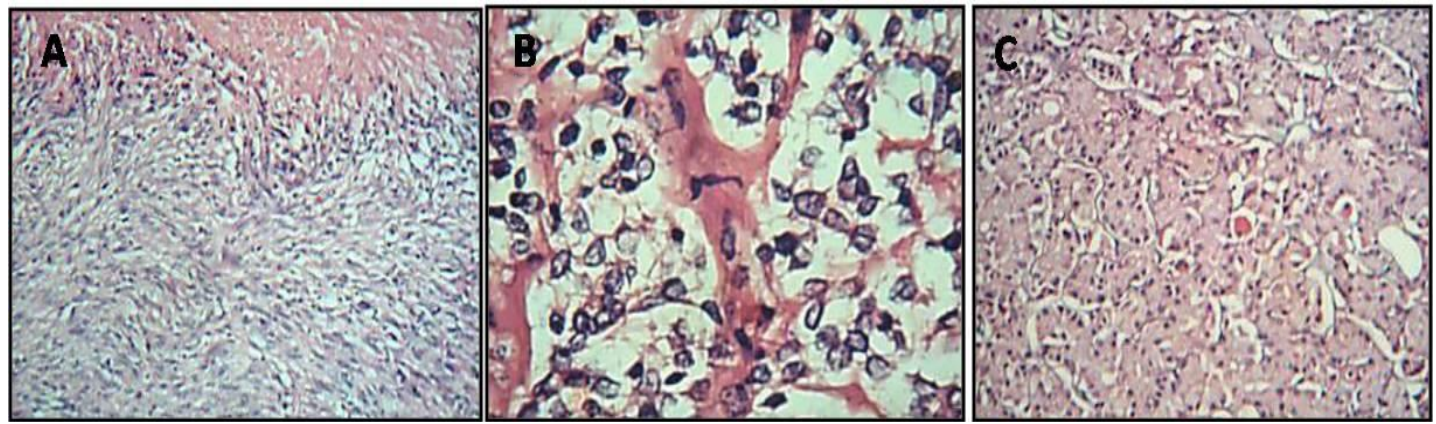

Fig. 3: A. Sarcomatoid variant of RCC; (B): Clear cell sarcoma of Kidney, C. Oncocytoma

\section{Discussion}

The kidney like other organs is liable to different diseases varying from congenital diseases, inflammatory and neoplastic lesion requiring nephrectomy. The results of this study enable us to pathologically classify the indications for nephrectomy.

In the present study among the 177 nephrectomy specimens, $36.2 \%$ cases were neoplastic conditions and rest $63.8 \%$ were non neoplastic conditions. Thus non neoplastic conditions comprised the majority of cases requiring nephrectomy similar to studies done by Ghalayani et $\mathrm{al}^{6}(70.44 \%)$, Rafique et $\mathrm{al}^{7}$ (76.6\%), Aiffa Aiman et $\mathrm{al}^{8}(77.2 \%)$, Abdulghafoor S et $\mathrm{al}^{9}(72.6 \%)$ and Kishor H. Suryawanshi et al ${ }^{1}(75.76 \%)$. However a higher incidence of neoplastic lesions of $52.9 \%$ and $58.46 \%$ were reported in studies done by Vikram Narang et $\mathrm{al}^{2}$ and Swarnlata Ajmera et $\mathrm{al}^{10}$ respectively.

A male to female ratio of 1.18:1 was noted when all the neoplastic and nonneoplastic conditions were considered together similar to studies done by Suryawanshi et al, ${ }^{1}$ Rafique et $\mathrm{al}^{7}$ and El Malik et al. ${ }^{11}$ In contrast a female predominance was reported by Shaila et $\mathrm{al}^{12}$ and Aiman et al. ${ }^{8}$

Nephrectomies showed a peak during $5^{\text {th }}-6^{\text {th }}$ decade followed by $3-4^{\text {th }}$ decade similar to Shaila et al ${ }^{12}$ study.

In the present study the most common indication for nephrectomy was chronic pyelonephritis $35.02 \%$, Table 1) followed by clear cell RCC $(18.10 \%)$ which is similar to studies done by Aiman et al, ${ }^{8}$ Popat et al, ${ }^{13}$ Suryawanshi et al $^{1}$ and Shaila et al. ${ }^{12}$

Neoplastic Diseases: Nephrectomy is a standard treatment offered to patients who present with benign as well as malignant mass lesions in the kidney. Most common malignant tumour in adults is renal cell carcinoma (RCC) and Wilms tumour in childhood. Rare are urothelial tumours of calyces and pelvis. Renal cell carcinoma (RCC) accounts for 1 to $3 \%$ of all visceral cancers and $85 \%$ of renal cancers. ${ }^{2}$

There was a male predominance among the neoplastic conditions similar to Suryawanshi et al, ${ }^{1}$ Ghalayini et al,${ }^{6}$ Anitha Padmanabhan et al ${ }^{3}$ and Sheikh Bilal et al. ${ }^{14}$

Majority of tumours were noted in 41-60 years age range (31 cases out of total 64 neoplastic conditions) similar to studies done by Anitha Padmanabhan et al, ${ }^{3}$ Suryawanshi et al ${ }^{1}$ and Sheikh Bilal et al. ${ }^{14}$

Majority of tumours involved left kidney similar to studies done by Swarnlata Ajmera et $\mathrm{al}^{10}$ and Sheikh Bilal et al. ${ }^{14}$

Clear cell renal cell carcinoma was the commonest tumor constituting 32 cases out of 64 neoplastic conditions $(50 \%)$ reported during our study period. Similarly highest incidence of clear cell RCC was reported in studies done by Rafique $\mathrm{M}^{\prime}$ et $\mathrm{al}^{7}(97 \%)$, Lopez et $\mathrm{al}^{15}(51 \%)$, Aiman et $\mathrm{al}^{8}(80 \%)$ and Eggener et $\mathrm{al}^{16}(76 \%)$.

Clear cell RCC was common in males and involved left kidney more often in this study. Furhman nuclear grading ${ }^{5}$ revealed 17 cases $(53 \%)$ showing grade 2 nuclear features and 10 cases $(31 \%)$ cases with grade 3 nuclear features similar to findings reported by Aiman et $\mathrm{al}^{8}$ and Popat et al. ${ }^{13}$

The other tumours in this study were 10 cases of Papillary RCC, 2 cases of multilocular cystic renal neoplasm of low malignant potential. Among the recently described RCC variants in latest WHO classification of Renal tumours, 3 cases of clear cell 
Papillary RCC and 1 case of tubulocystic RCC was diagnosed in this study period.

There were 2 cases of Sarcomatoid variant of RCC in this study which was reclassified as RCC unclassified according to the latest WHO classification of renal tumours. ${ }^{5}$

In the present study 6 Wilms tumor cases were reported, among them 2 cases were in adult age group, which is rare and was diagnosed following Kilton's criteria. ${ }^{17}$ All the paediatric Wilms tumor cases were female patients with mean age at presentation of 5.5 years.

Benign tumours of the kidney are rarely found in nephrectomy specimens but are common in post mortem examination and as an incidental finding in imaging study during life. ${ }^{9}$ Among the benign tumours of kidney there were 3 cases $(1.69 \%)$ of oncocytoma and angiomyolipoma each. The incidence of oncocytoma in this study was similar to that reported by Vikram Narang et al. ${ }^{2}$ Incidence of angiomyolipoma was slightly lower than that reported in Abdulghafoor study. ${ }^{9}$

Non Neoplastic Diseases: In the present study, the most common indication for nephrectomy was Chronic pyelonephritis similar to Aiman et $\mathrm{al},{ }^{8}$ Shaila et al, ${ }^{12}$ Popat et $\mathrm{al}^{13}$ and Abdulghafoor et al. ${ }^{9}$ There was a slight female predominance similar to Abdulghafoor et $\mathrm{al}^{9}$ study. Majority of cases were noted in 41-60 age range in contrats to Suryawanshi et al ${ }^{1}$ study where majority of cases were in 21-40 age range.

The next common non neoplastic condition noted in the present study was Hydronephrosis which was mainly due to calculus etiology and also showed features of chronic pyelonephritis. The incidence of Hydronephrosis was $11.9 \%$ in the present study which was similar to Kotta Devender Reddy et al ${ }^{18}$ study $(12.9 \%)$. There were 12 cases $(6.8 \%)$ of Xanthogranulomatous nephritis in this study similar to Aiman et $\mathrm{al}^{8}(5.7 \%)$ and Kotta Devender Reddy et $\mathrm{al}^{18}$ study (10.3\%). There was female predominance similar to Aiman et $\mathrm{al}^{8}$ study. In contrast a male predominance was noted in Suryawanshi et $\mathrm{al}^{1}$ study. Majority of cases were in 41-60 age range similar to Aiman et $\mathrm{al}^{8}$ study.

Renal tuberculosis is common in developing countries as compared to developed countries and patients present with sterile pyuria. In the present study, 5 cases $(2.82 \%)$ of tuberculosis of kidney were reported similar to Ghalayani et $\mathrm{al}^{6}(2.1 \%)$. A Slight higher incidence was reported by Kotta Devender Reddy et $\mathrm{al}^{18}(7.7 \%)$.

The other non neoplastic lesions with lesser incidence noted in this study were chronic interstitial nephritis (5 cases), end stage tubule interstitial disease (3 cases), simple renal cysts (2 cases), Hypoplastic cystic renal dysplasia (1 case), Adult polycystic kidney (1 case) and actinomycosis (1 case).

\section{Conclusion}

The present study provides a fair insight into the histological patterns of lesions in nephrectomy specimens in our institution and its correlation with studies conducted across the world. Open nephrectomy still remains treatment of choice for the both neoplastic and nonneoplastic conditions. A detailed Histopathological examination of every specimen should be done to help in clinic-morphological correlation and proper management. Chronic pyelonephritis was the most common indication for nephrectomy. The most common pediatric tumor was Wilms tumor and adult tumor was clear cell RCC in our study.

\section{References}

1. Suryawanshi K H, Damle R P, Dravid N V, Rawandale A $\mathrm{P}$ and Surana A. Histomorphological Analysis of Lesions In Nephrectomy Specimens: A 4 Years Study In A Rural Hospital In India-Our Experience. Annals of Pathology and Laboratory Medicine. 2017;4:230-235.

2. Narang V, Garg B, Walia A, Sood N, Malhotra V. Histomorphological Spectrum of Nephrectomy Specimens- A Tertairy Care Centre Experience. National Journal of Laboratory Medicine. 2016;5:51-54.

3. Padmanabhan A, Sachdeva P, Gadgil N M. Clinicopathological study of adult renal tumours. Indian Journal of Pathology and Oncology. 2016;3:202-211.

4. Ngairangbam S, Konjengbam R. Histopathological spectrum of non-neoplastic and neoplastic lesions in nephrectomy specimens. J Evid Based Med. Healthc. 2016;3:627-629.

5. WHO classification of Tumours: Pathology and genetics of tumours of urinary system and male genital organ. 2016;9-87.

6. Ghalayini I F. Pathological Spectrum of Nephrectomies in a General Hospital. Asian Journal of Surgery. 2002;25:163-169.

7. Rafique M. Nephrectomy: Indications, complications and mortality in 154 consecutive patients. J Pak Med Assoc. 2007;57(6):308-311.

8. Aiman A, Singh K, Yasir M. Histopathological spectrum of lesions in nephrectomy specimens: A five year experience in a tertiary care hospital. $J$ Sci Soc. 2013;40(3):148-54.

9. Abdulkareem A S, Hassawi B A, Ahmed Z. Nephrectomy. A clinicopathological study. Journal of American Science. 2015;11(8):97-101.

10. Ajmera S, Ajmera R. Histopathological Spectrum of Lesions in Nephrectomies- A Five Year Study. 2017;6:44-46.

11. El Malik EM, Memon SR, Ibrahim AL, Al Gizavi A, Ghali AM. Nephrectomy in Adults: Asir Hospital Expirience. Saudi J Kidney Dis Transpl. 1997;8:423-7.

12. Shaila, Nityananda BS, Tamil Arasi. Spectrum of lesions in nephrectomy specimens in tertiary care hospital. Journal of evolution of medical and dental sciences. 2015;4(73):12714-12726.

13. Popat VC, Kumar MP, Udani D, Mundra MP, Vora DN, Porecha MM. A study on culprit factors ultimately demanding nephrectomy. Internet J Urol. 2010;7.

14. Bilal S, Farooq S, Beigh A, Reshi R, Beigh A, Manzoor F. Clinicopathological study of adult malignant renal tumours in Kashmir. International Journal of Medical Science and Clinical Invention. 2017;4:2710-2714. 
15. López JI, Moreno V, García H, Antón I, Robles A, Oñate JM, et al. Renal cell carcinoma in young adults: a study of 130 cases and a review of previous series. Urol Int. 2010;84:292-300.

16. Eggener SE, Rubenstein JN, Smith ND, Nadler RB, Kontak J, Flanigan RC, et al. Renal tumors in young adults. J Urol. 2004;171:106-10.

17. Kilton L, Mathews MJ, Cohen MH. Adult Wilm's' tumour: a [4] report of prolonged survival and review of literature. J Urol. 1980;124(1):1-5.
18. Reddy K D, Gollapalli S, Sujitha C, Sidagam S, Mohmmed A K, Bommana A. A Clinico-Morphological Spectrum of Nephrectomy Specimens - An Experience from a Tertiary Care Hospital. 2016;6:67-72.

How to cite this article: Chaitra B, Prema LP, Tejeswini V, Haritha O, Anusha M. Histopathology of nephrectomy specimens: A ten year south Indian tertiary hospital based study. J Diagn Pathol Oncol. 2018;4(3):232-236. 